\title{
ENVIRONMENTAL POLICY UNDER MODEL UNCERTAINTY: A RoBust Optimal CONTROL APPROACH
}

\author{
MICHAEL FUNKE \\ MICHAEL PAETZ
}

CESIFO WORKIng PAPER NO. 1938

CATEGORY 8: RESOURCES AND ENVIRONMENT

MARCH 2007

An electronic version of the paper may be downloaded

- from the SSRN website:

- from the RePEc website:

www.SSRN.com

- from the CESifo website: 


\title{
ENVIRONMENTAL POLICY UNDER MODEL UNCERTAINTY: A RoBUst OPTIMAL CONTROL APPROACH
}

\begin{abstract}
Model uncertainty is inherent in the design of optimal environmental policy. We investigate the consequences in a simple linear model, where the aim of the policymaker is to stabilize the carbon content of the atmosphere. We study how decision-makers' concerns about robustness alter policy using the Hansen and Sargent $(2000,2003,2007)$ approach. The analysis shows that a policymaker, who fears model misspecification should react more aggressively to changes in the stock of atmospheric carbon and implement policies which deliver a greater reduction of emissions.
\end{abstract}

JEL Code: C61, Q25, Q28, D81.

Keywords: robust control model uncertainty, environmental policy.

\author{
Michael Funke \\ Hamburg University \\ Department of Economics \\ Von-Melle-Park 5 \\ 20146 Hamburg \\ Germany \\ funke@econ.uni-hamburg.de
}

\author{
Michael Paetz \\ Hamburg University \\ Department of Economics \\ Von-Melle-Park 5 \\ 20146 Hamburg \\ Germany \\ paetz@econ.uni-hamburg.de
}

Hamburg, March 2007

Insightful comments from Richard Tol on an earlier draft helped to shape this paper. The usual disclaimer applies. 


\section{Introduction}

Model uncertainty is an important issue in the context of environmental policy for at least two reasons: First, existing knowledge of the evolution of the ecological system is still somewhat speculative (physical system uncertainty). ${ }^{1}$ Second, there is a deficiency of accurate information regarding the future costs of environmental damage or future benefits from avoiding it (economic uncertainty). ${ }^{2}$ Therefore, the uncertainty inherent in environmental and economic modelling is receiving increasing attention and many policymakers are worried about the "unknown unknowns".

Several studies have analysed the impact of uncertainty on optimal timing problems [see for example Pindyck (2000) or Pindyck (2001)]. Baker (2005), Keller et al. (2004) and Webster (2002) have discussed the question of acting now or waiting in an integrated assessment model with active learning. Baker et al. (2006) have discussed the point that channelling R\&D efforts into technologies with low emissions may serve as a hedge against uncertainty. Webster et al. (2003) calculate probability distribution functions for uncertain parameters in ecological models and provide probability distributions for future climate projections based on current uncertainty in model parameters.

In this paper we focus on one particular aspect of uncertainty, namely how optimal policy decisions depend upon uncertainty about the "true" model. In other words, we contribute to the uncertainty literature by studying how environmental policymakers' concerns about model robustness alter optimal environmental policy. In contrast to stochastic control, robust control methods seek to bound the uncertainty rather than express it in the form of a probability distribution. Given a bound on the uncertainty, the control can deliver results that meet the control system requirements in all potential cases. Therefore robust control theory may be seen as a worst-case analysis method rather than a typical case method. Thus, the procedure is particularly suitable to deal with low-probability extreme climate events.

To reflect the policymaker's concerns over misbehaving models, we use recently developed robust control techniques by Hansen and Sargent (2000, 2003, 2007, henceforth HS). HS have initiated a research agenda that introduces the notion of robustness into model uncertainty and addresses

\footnotetext{
${ }^{1}$ The recently published fourth assessment report of the Intergovernmental Panel on Climate Change (IPCC) illustrates a curious aspect of the science of climate change. Studying the climate system reveals new, little understood, mechanisms and feedback effects that may increase or decrease warming. So as understanding grows, predictions become less, rather than more certain. Thus, the IPCC's range of predictions of the rise in the temperature by 2100 has increased from $1.4-5.8 \%$ in the 2001 report to $1.1 .-6.4 \%$ in the latest report (see http://www.ipcc.ch/).

${ }^{2}$ Most economists reckon that, if greenhouse-gas emissions continue on their current path, the costs of climate change would be between zero (where the benefits of warming to cold countries balances out the costs) and $3 \%$ of global GDP over the next 100 years. See, for example, Ingham and Ulph (2003) for a survey about uncertainty concerning the calculations of the social costs of carbon and Tol (2005) for a summary of 103 empirical studies on the marginal costs of carbon. Paraphrasing a quote from Alan Greenspan on monetary policy uncertainty one may say: "Uncertainty is not just an important feature of the environmental economics landscape, it is the defining characteristic of that landscape".
} 
concerns about model misspecification. Methodologically they modify techniques from the robust control literature in applied mathematics. In a nutshell, the fundamental idea of robustness is that economic and environmental models are best viewed as stylised approximations of reality rather than perfect descriptions thereof. When policy-makers use a particular model as guidance in a dynamic decision-making situation and worry that the model may be misspecified, one would expect them to insist on considering alternative models in order to obtain decision rules that not only work well within the baseline model but also work reasonably well when the model is misspecified. It is in this sense that a policy is designed to be robust. In this paper, however, policymakers are assumed to achieve robustness by considering a worst-case model that is similar to and statistically difficult to distinguish from the baseline model. In other words, the policymaker considers a set of alternative models which are "close" to the baseline model, where distance between the models is measured by an entropy or likelihood-type criterion.

In the existing literature, this methodology has been extensively used for the design of monetary policy under uncertainty. It has overturned Brainard's (1967) conservatism principle and provides a rationale for monetary policy reacting more aggressively to changes in output and inflation under model uncertainty compared to an environment without model uncertainty. The only application of this technique in an environmental model so far is Roseta-Palma and Xepapadeas (2004). In their paper the fishery management problem is handled using robust optimal control, where the objective is to choose a harvesting rule that will work, in the sense of preventing instabilities and overfishing, under a range of admissible specifications for the stock recruitment equation. The main topic of our paper is to analyse robust $\mathrm{CO}_{2}$ abatement policies in an uncertain modelling context.

The paper proceeds as follows. As a foundation for the subsequent analysis, in Section 2 we briefly introduce the notion of robustness laid out by HS. The baseline model is introduced in Section 3. Building on the robustness concept, in Section 4 we proceed to an analysis of the scenario where a policymaker faces uncertainty regarding the model on which he bases his optimal policy decisions. Section 5 summarises and draws some conclusions.

\section{Hansen-Sargent Robustness}

Misgivings over models have existed for as long a time as models themselves. This section gives an intuitive introduction to the recently developed concept of HS robustness, which deals with uncertainty by deriving optimal solutions in a restricted worst case model, where the restriction in turn depends on the underlying model. ${ }^{3}$

\footnotetext{
${ }^{3}$ A high volume of research in robust control over the past 15 years has led to a growth in techniques. The following methodological piece draws upon the more complete discussions in HS. The description of the technique focuses both upon the overall concept and on the details of the mathematics.
} 
The core idea is to treat the decision maker's model as an approximation of the true model. Let $x$ be a vector of state variables and let the true data follow a Markov-process with a transition density $f\left(x^{*} \mid x\right) .{ }^{4}$ Moreover, let the approximating model be described by a transition density $f_{d}\left(x^{*} \mid x\right)(\alpha \in A$, where $A$ denotes a compact set of parameter values). Then the maximum likelihood estimator $\hat{\alpha}_{0}$ would be derived by minimizing the relative entropy of $f$ and $f_{\alpha}[I(\alpha, f)]$, which measures the "expected distance" between $f$ and $f_{\alpha}$ and is defined as the expectation of the log likelihood ratio conditioned on the approximating model. The HS methodology inverts this approach by taking $f_{\alpha}$ as given, and builds a set of possible data generating processes around this model, so that the true model is one model in this set. This is graphically shown in Figure 1.

\section{Figure 1: An Econometrician vs. a Hansen-Sargent Robust Policymaker \\ [Adopted from Hansen and Sargent (2007)]}

\section{Econometrician}

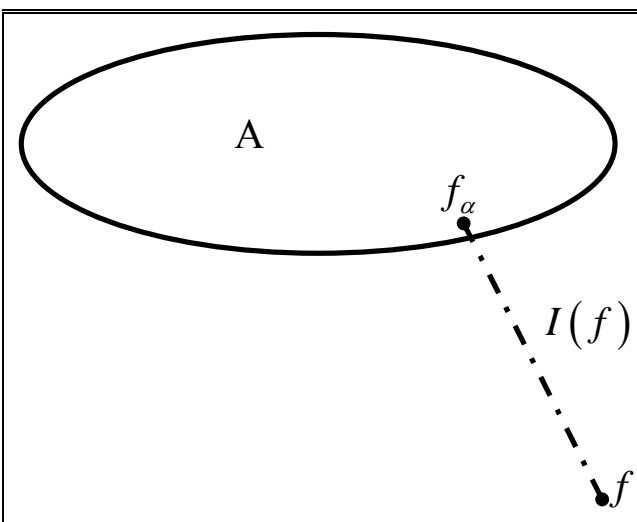

Hansen-Sargent Robust Policymaker

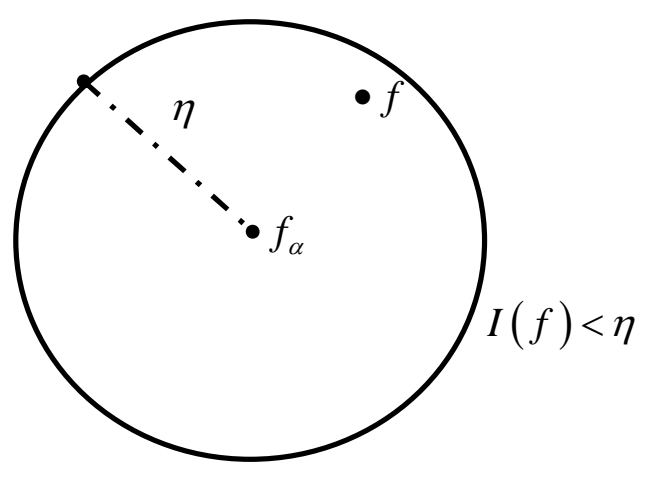

Note: Whereas an econometrician would minimise the distance between $f$ and $f_{\alpha}$, a HS robust policymaker takes $f_{\alpha}$ as given and derives the worst case solution in a set of possible data generating processes around $f_{\alpha}$.

A standard result in optimal control theory is certainty equivalence, which results under the assumption of a linear model with additive uncertainty and a quadratic loss function. Certainty equivalence implies that only the mean values, i.e. the probability-weighted average outcomes of target variables matter for the optimal setting. Certainty equivalence therefore implies that low probability disturbances should not be taken into account, only the first (statistical) moment matters for policy, not the higher moments. In order to come to grips with this problem, robust control theorists add an additional vector process $\left\{\omega_{t+1}\right\}$ to the model that depends in a possibly non-linear way on the history of the state variables:

$$
x_{t+1}=A x_{t}+B u_{t}+C\left(\varepsilon_{t+1}+\omega_{t+1}\right)
$$

\footnotetext{
$4^{*}$ denotes next period values.
} 
where $u$ denotes a vector of control variables, and $A, B$ and $C$ are matrices, filled with appropriate structural parameters. ${ }^{5}$ For convenience, let us assume that the loss function of the decision maker is convex and given by $r(x, u)=|z|^{2}$. Then the robust problem can be reduced to the following Bellman equation:

$$
V(x)=\min _{\left\{u_{t}\right\}} \max _{\left\{\omega_{t+1}\right.} E_{t}\left\{z^{\prime} z-\theta \delta w^{* \prime} w^{*}+\delta V\left(x^{*}\right)\right\}
$$

subject to equation (1) where $E$ is the expectations operator and $\theta>0$ represents the decision maker's preference for robustness. The preference for robustness falls as $\theta$ rises, so that the problem is equal to its non-robust version when $\theta$ reaches infinity.

In equation (2) the usual minimisation problem is transformed into a min-max problem. The solution of equation (2) now incorporates the worst case $\omega$ as a function of $x$ and $u$ and the corresponding decision rule $u=-F x$ depends on $C$. Intuitively, the policymaker wants to minimise the maximum welfare loss due to model misspecifications by specifying an appropriate environmental policy which shields the economy from the worst possible scenario. The additional process can be interpreted as a second malevolent player (often referred to as "the imaginary evil agent"), trying to distort the model as much as possible. ${ }^{6}$

To restrict the second player, who would otherwise distort the model without bounds, the decision maker uses an inter-temporal extension of relative entropy:

$$
R(\omega)=2 E_{0} \sum_{t=0}^{\infty} \delta^{t+1} I(\alpha, f)=E_{0} \sum_{t=0}^{\infty} \delta^{t+1} \omega^{\prime} t+1 \omega_{t+1} \leq \eta_{0}
$$

In equation (3) and in Figure 1, the set of distorted models can be seen as a sphere around the approximating model with $\eta_{0}$ defining the radius of the sphere. Intuitively, model uncertainty manifests itself through just one additional parameter, although the framework covers a wide range of misspecified dynamics including wrong parameters $\left(v_{t+1}\right.$ is a linear function of $x_{t}$ ), autocorrelated errors $\left(v_{t+1}\right.$ is a linear function of $\left.x_{t}\right)$, and/or ignored nonlinearities $\left(v_{t+1}\right.$ is a nonlinear function of $\left.x_{t}\right){ }^{7}$ It can be verified that the restriction upon the evil agent (the choice of $\eta_{0}$ ) depends on $\theta$. Thus, all

\footnotetext{
${ }^{5}$ Note that the additional shock terms are given by $\omega_{t+1}$. Therefore the misspecification of the model is masked by the shock terms $\varepsilon_{t+1}$ and cannot be observed.

${ }^{6}$ The fictitious second rational agent is a metaphor. Nevertheless, one interpretation may be to consider country 1 that tries to reduce emissions but is afraid that country 2 will undo all its good work. Thus country 2 would alter the properties of the model.

${ }^{7}$ This is an advantage as it simplifies the analysis, but it also implies that it is not possible to study the impact of specific types of uncertainty. The standard modelling approach without model uncertainty corresponds to $\eta_{0}=0$.
} 
types of misspecification are handled by specifying only one parameter, $\theta{ }^{8}{ }^{8}$ A lower $\theta$ means that the policymaker designs a policy which is appropriate for a wider set of model misspecifications. Therefore, a lower $\theta$ is equivalent to a higher degree of robustness.

The choice of the robustness parameter is therefore crucial for the choice of a plausible range of model uncertainty. ${ }^{9}$ To overcome the problem of specifying an arbitrary range for $\theta$, we follow HS and employ what they refer to as a detection error probability approach. The basic idea is that the alternative models a policymaker faces should not be easily distinguishable when one uses a reasonable set of data. HS employ statistical theory to formulate a probability for discriminating between the approximating model and the distorted model and, consequently, to obtain a modelspecific $\theta$. With equal prior weights, the Bayesian detection error probability is defined as $p(\theta)=1 / 2$ $\left(p_{a}+p_{d}\right)$, where $p_{i}$ represents the frequency of simulations with a log likelihood ratio smaller or equal to zero, when the approximating $(i=a)$ or the distorted $(i=d)$ model is assumed to be the data generating process. HS suggest setting $p(\theta)$ at a plausible value and then inverting $p(\theta)$ to find a plausible value for the robustness parameter. They advise using a value for the detection error probability of around $10 \%$ in a sample of size 150 .

The HS approach presented above will facilitate the analysis of environmental policy under model uncertainty in the coming sections.

\section{The Baseline Model}

The reduced-form baseline model is in the spirit of Pindyck (2001). However, we do not study the optimal timing of adopting an irreversible policy. Instead, we focus on the question of whether a stabilisation policy should be more aggressive when a policymaker is concerned about uncertainty. We assume that the authority is able to control the path of emissions, but do not specify possible policies, such as taxes on emissions, the adoption of new technologies or the sequestering of carbon from the atmosphere in sinks, respectively. Moreover, we assume that reducing emissions is costly. For convenience, and for illustrative purposes, our analysis focuses on the concentration of carbon. However, this approach can be used for any other stock of environmental pollutants which fulfil the following assumptions. Let $C A_{t}$ be a state variable, representing the average concentration of carbon in the atmosphere, and $\mathrm{CO}_{t}$ be the control variable, representing the rate of $\mathrm{CO}_{2}$ emissions. ${ }^{10}$ Then the evolution of $C A_{t}$ can be described by

\footnotetext{
${ }^{8}$ In fact, the size of $\omega_{\mathrm{t}+1}$ is directly penalized through $\theta$, which is equivalent to the Lagrange multiplier on (2) in a min-max problem $E_{0}\left(\sum r\left(x_{t}, u_{\mathrm{t}}\right)\right)$ subject to (1) and (3).

${ }^{9}$ Given this feature of HS robustness, Svensson (2002) has argued that a robust planner could also be a fool, worrying too much over implausible catastrophes, just by setting the value for $\theta$ too low.

${ }^{10} \mathrm{We}$ assume that without policy intervention, $C O_{t}$ follows an exogenous trajectory.
} 


$$
C A_{t}=(1-\kappa) C A_{t-1}+\beta C O_{t-1}+e_{C A, t}
$$

where $\kappa$ is the rate at which $\mathrm{CO}_{2}$-emissions rise the average concentration of carbon in the atmosphere, $\beta$ represents the natural rate at which the stock of carbon concentration dissipates, and $e_{C A, t}$ represents a Gaussian identically and independently distributed (i.i.d.) shock process with zero mean and a variance of one. This shock captures all exogenous disturbances, which influence the evolution of the carbon concentration, and are not involved in equation (4). If the policymaker aims at stabilising the atmospheric concentration of carbon, equation (4) leads to the equilibrium condition $\left(C A_{t}=C A_{t-1}=C A, C O_{t}=C O_{t-1}=C O\right)$

$$
C A=\frac{\beta}{\kappa} C O
$$

By subtracting the equilibrium relationship, equation (4) can be expressed in absolute differences from equilibrium:

$$
c a_{t}=(1-\kappa) c a_{t-1}+\beta c O_{t-1}+e_{c a, t},
$$

where lower case letters represent absolute deviations from equilibrium, for example $\mathrm{CO}_{t}=\mathrm{CO}_{t}-\mathrm{CO}$. We assume the following loss-function, representing the preference for a stabilisation of carbon concentration around a particular equilibrium value

$$
L_{t}=\gamma\left(c a_{t}\right)^{2}
$$

where $\gamma$ reflects the preference for stabilisation and influences the speed of convergence to equilibrium. ${ }^{11}$ Following Baker $\left(2005\right.$, p. 24), we assume that the costs $C_{t}$ of reducing emissions by a particular policy are a quadratic function of the reduction $\Delta C \mathrm{CO}_{t}{ }^{12}$ Formally,

$$
C_{t}=\lambda\left(\mathrm{CO}_{t}-\mathrm{CO}_{t-1}\right)^{2}=\lambda\left(\mathrm{CO}_{t}-\mathrm{CO} t-1\right)^{2}
$$

\footnotetext{
${ }^{11}$ The loss function (7) is a shortcut, which suppresses the fact that policymakers in democratic societies are under pressure from various interest groups and therefore have to enact environmental regulation through a lengthy political bargaining process.

${ }^{12}$ Pindyck (2001) has assumed a linear cost function for simplicity, but mentioned that one would generally expect costs to be convex.
} 
where $\lambda$ reflects the quadratic costs of mitigation. The goal of the social planner is to stabilize the carbon concentration on a predetermined equilibrium value under minimal costs of mitigation policies

$$
\begin{aligned}
& \min _{\left\{c o_{t}\right\}} E_{0} \sum_{t=0}^{\infty} \delta^{t}\left(L_{t}-C_{t}\right) \\
& \Leftrightarrow \max _{\left\{c o_{t}\right\}}-\left\{E_{0} \sum_{t=0}^{\infty} \delta^{t}\left(L_{t}-C_{t}\right)\right\} \\
& \Leftrightarrow \max _{\left\{c o_{t}\right\}} E_{0} \sum_{t=0}^{\infty} \delta^{t}\left(\lambda\left(c o_{t}-c o_{t-1}\right)^{2}-\gamma\left(c a_{t}\right)^{2}\right)
\end{aligned}
$$

subject to (6), where $\delta$ represents the discount factor. However, the policymaker knows that the model could be subject to a range of distortions. Therefore, the task is to reformulate the optimisation problem such that the resulting policy rule performs sufficiently well even if the model deviates from the baseline model.

\section{Optimal Robust Policy}

Keeping the preceding analysis in mind, let us now examine the resulting optimal robust policy. To solve for the optimal solution we construct the Lagrangian for the problem

$$
\max _{\left\{c o_{t}\right\}} E_{t} \sum_{i=0}^{\infty} \delta^{i}\left[\lambda\left(c o_{t+i}-c o_{t+i-1}\right)^{2}-\gamma\left(c a_{t+i}\right)^{2}+\psi_{t+i}\left((1-\kappa)_{c a_{t+i-1}}+\beta c o_{t+i-1}-c a_{t+i}\right)\right]
$$

where $\left\{\psi_{t+i}, i \geq 0\right\}$ is the sequence of Lagrangian multipliers. For simplicity we solve the problem as if the social planner is able to choose optimal values for $\left\{\mathrm{co}_{t+i}, i \geq 0\right\}$ and $\left\{c a_{t}, i \geq 0\right\}$. In a second step we then solve for the optimal path of the control variable $\left\{\mathrm{CO}_{t}\right\}$. The first order conditions from (10) are given by

$$
\begin{aligned}
& \left\{c o_{t+i}\right\}: 2 \lambda \delta^{i} E_{t}\left(\Delta c O_{t+i}\right)-2 \lambda \delta^{i+1} E_{t}\left(\Delta c O_{t+1+i}\right)+\beta \delta^{i+1} E_{t}\left(\psi_{t+1+i}\right)=0 \\
& \left\{c a_{t+i}\right\}: \quad 2 \gamma \delta^{i} E_{t}\left(c a_{t+i}\right)=(1-\kappa) \delta^{i+1} E_{t}\left(\psi_{t+1+i}\right)-\delta^{i} E_{t}\left(\psi_{t+i}\right)
\end{aligned}
$$

Transforming (11) leads to 


$$
E_{t}\left(\psi_{t+1+i}\right)=2(\lambda / \beta)\left[E_{t}\left(\Delta c O_{t+1+i}\right)-\delta^{-1} E_{t}\left(\Delta c O_{t+i}\right)\right]
$$

which can be used in (12) to derive the social optimal path of emissions:

$$
\Delta c O_{t}=-\left(\frac{\gamma \beta}{\lambda \kappa}\right) c a_{t}+\frac{1}{\kappa}\left[(1-\kappa)\left(\Delta c O_{t+1}\right)+\frac{1}{\delta}\left(\Delta c O_{t-1}\right)\right],
$$

where we use $E_{t}\left(C O_{t+i}\right)=c O_{t+i}(\forall t, i)$, since we assume that the policymaker controls emissions. The optimal amount of additional emissions at time $t$ depends negatively on the deviation of the concentration of carbon from equilibrium, but positively on $\Delta \mathrm{co}_{t+1}$ and $\Delta \mathrm{CO}_{t-1}$ - where future values are discounted and lagged values are projected. The first term reflects the fact that a higher deviation in the concentration of carbon causes higher social costs and tends to reduce the optimal amount of emissions when concentrations are above equilibrium. The second term reflects the fact that a higher reduction of emissions inflicts costs. Therefore this term smoothes the path of emissions. With rising $\beta$, the influence of emissions on the average carbon concentration increases and emissions should be lowered. The same holds for $\gamma$, since $\gamma$ reflects the preference for carbon stabilisation and punishes deviations of the average carbon concentration from equilibrium. For $\lambda$ the opposite is true: when the costs of reducing a particular amount of emissions rises, the optimal amount increases. As the stock of carbon concentration dissipates at a higher rate, emissions become less damaging and also increase the expression $\left(\partial \Delta c o_{t} / \partial \kappa>0\right)$. Equations (6) - (9) can be transformed into a standard stochastic optimal control approach

$$
V=\max _{\left\{u_{t}\right\}} E_{0}\left[\sum_{t=0}^{\infty} \delta^{t}\left(x^{\prime}{ }_{t} Q x_{t}+2 x^{\prime}{ }_{t} U u_{t}+u^{\prime}{ }_{t} R u_{t}\right)\right]
$$

subject to $x_{t+1}=A x_{t}+B u_{t}+\varepsilon_{t+1}$ where

$$
x_{t}=\left[\begin{array}{l}
c O_{t-1} \\
c a_{t}
\end{array}\right], u_{t}=c O_{t}, \varepsilon_{t+1}=\left[\begin{array}{l}
\varepsilon_{c o, t+1} \\
\varepsilon_{c a, t+1}
\end{array}\right], Q=\left[\begin{array}{cc}
\lambda & 0 \\
0 & -\lambda
\end{array}\right], U=\left[\begin{array}{l}
-\lambda \\
0
\end{array}\right], R=\lambda, A=\left[\begin{array}{cc}
0 & 0 \\
0 & (1-\kappa)
\end{array}\right], B=\left[\begin{array}{l}
1 \\
\beta
\end{array}\right]
$$

The sequence $\left\{e_{c o, t+1}\right\}$ is a second i.i.d. shock process with zero mean and a variance of one, and captures the fact that emissions can not be perfectly controlled by the policymaker. In order to incorporate concern for model misspecification when using HS robust modelling techniques, the resulting max-min-problem can be transformed into a standard RE-program 


$$
V=\max _{\left\{u_{t}\right\}} \min _{\left\{\omega_{t+1}\right.} E_{0}\left[\sum_{t=0}^{\infty} \delta^{t}\left(x_{t}^{\prime} \widetilde{Q}_{t}+2 x^{\prime}{ }_{t} \widetilde{U} \widetilde{u}_{t}+\widetilde{u}_{t}^{\prime} \widetilde{R} \widetilde{u}_{t}\right)\right]
$$

subject to $x_{t+1}=A x_{t}+\widetilde{B} \widetilde{u}_{t}+\varepsilon_{t+1}$ where

$$
\widetilde{U}=\left[\begin{array}{ll}
U & 0
\end{array}\right], \widetilde{R}=\left[\begin{array}{cc}
R & 0 \\
0 & -\theta I_{2}
\end{array}\right], \widetilde{B}=\left[\begin{array}{ll}
B & I_{2}
\end{array}\right], F=\left(\begin{array}{l}
F_{u} \\
F_{\omega}
\end{array}\right) \text { and } \widetilde{u}_{t}=\left(\begin{array}{c}
u_{t} \\
\omega_{t}
\end{array}\right) \text {. }
$$

Equation (16) completely characterises the optimal policy strategy taking environmental model uncertainty into account explicitly.

Since we believe that plausible values for the stabilization preference should be related to marginal costs of $\mathrm{CO}_{2}$-emissions, we use empirical studies on marginal costs to derive plausible values for $\gamma$. The marginal damage cost is defined as the net present value of the incremental damage due to a marginal increase in $\mathrm{CO}_{2}$ emissions. Unfortunately, with regard to suitable values for almost all parameters there exists wide disagreement between experts. Therefore it is crucial to subject all results to sensitivity testing. Our marginal cost estimates are derived from Tol (2005), who summarizes 103 empirical studies and builds one composite probability density function for all studies. As we believe that estimates should withstand a quality test, we rely only on peer-reviewed studies and use the mode ( 5 /ton of carbon), the mean (50\$/tC), the median (14 \$/tC), the 5\% percentile (-9 \$/tC) and the 95\% percentile $(245 \$ / \mathrm{tC})$ from Tol's (2005) density function for those studies.

For the costs of mitigation we rely on the estimates of Van Vuuren et al. (2006) who summarize results from 18 different model approaches, and run simulations for the highest and the lowest values, as well as for the mean of all studies. The rate of dissipation $(\kappa)$ is assumed to be 0.01 , and for the rate at which emissions raise the average concentration of carbon $(\beta)$ we use a value of 0.99 . For the discount factor we assume the standard value for yearly periods of 0.96 .

Formally, policy rules resulting from the optimisation problem (16) solve for the optimal strategy and are of the form $c O_{t}=a c O_{t-1}+b c a_{t}$. 
Table 1: Optimal Policy Rule Parameters $(a, b)$

\begin{tabular}{|c|cc|cc|cc|}
\hline \multirow{2}{*}{$\lambda$} & \multicolumn{2}{|c|}{$5600 \$ / \mathrm{Gt}^{2}$} & \multicolumn{2}{c|}{$202600 \$ / \mathrm{Gt}^{2}$} & \multicolumn{2}{c|}{$224000 \$ / \mathrm{Gt}^{2}$} \\
\cline { 2 - 7 } & $\theta=\infty$ & $\mathrm{p}(\theta) \approx 10 \%$ & $\theta=\infty$ & $p(\theta) \approx 10 \%$ & $\theta=\infty$ & $p(\theta) \approx 10 \%$ \\
\hline$-0.09 \$ / \mathrm{Gt}^{2}$ & $(0.5027$, & $(0.4007$, & $(0.5024,0)$ & $(0.4007,0)$ & $(0.5024,0)$ & $(0.4008,0)$ \\
& $0.0001)$ & $0.0002)$ & & & & \\
\hline Loss & 559970 & 636320 & 20244000 & 23020000 & 22380000 & 25448000 \\
\hline $0.05 \$ / \mathrm{Gt}^{2}$ & $(0.5025$, & $(0.4009$, & $(0.5024,0)$ & $(0.4007,0)$ & $(0.5024,0)$ & $(0.4008,0)$ \\
& $-0.0001)$ & $-0.0001)$ & & & & \\
\hline Loss & 560000 & 636110 & 20244000 & 23020000 & 22380000 & 25448000 \\
\hline $0.14 \$ / \mathrm{Gt}^{2}$ & $(0.5023$, & $(0.4008$, & $(0.5024,0)$ & $(0.4007,0)$ & $(0.5024,0)$ & $(0.4008,0)$ \\
& $-0.0002)$ & $-0.0003)$ & & & & \\
\hline Loss & 560010 & 636090 & 20244000 & 23020000 & 22380000 & 25448000 \\
\hline $0.5 \$ / \mathrm{Gt}^{2}$ & $(0.5018$, & $(0.4010$, & $(0.5024,0)$ & $(0.4007,0)$ & $(0.5024,0)$ & $(0.4008,0)$ \\
& $-0.0007)$ & $-0.0009)$ & & & & \\
\hline Loss & 560070 & 635740 & 20244000 & 23020000 & 22380000 & 25448000 \\
\hline $2.45 \$ / \mathrm{Gt}^{2}$ & $(0.4996$, & $(0.4$, & $(0.5023$, & $(0.4007$, & $(0.5023$, & $(0.4008$, \\
& $-0.0029)$ & $-0.0039)$ & $-0.0001)$ & $-0.0001)$ & $-0.0001)$ & $-0.0001)$ \\
\hline Loss & 560340 & 635320 & 20244000 & 23019000 & 22381000 & 25448000 \\
\hline
\end{tabular}

In Table 1 results for $(a, b)$ are given for different values of $\lambda$ and $\gamma$ for the robust and the non-robust case. Robust solutions are computed for a robustness parameter $\theta$ that corresponds to a detection error probability near $10 \%$ in a sample of 150 , using Monte Carlo simulations. Several points deserve further emphasis. All parameter combinations clearly show that losses become greater under uncertainty, and that a robust policymaker should react more aggressively on deviations of carbon from equilibrium. Furthermore, all reaction parameters on last period's emissions decrease (increase in absolute value), which can also be interpreted as a more aggressive stabilization policy. ${ }^{13}$ Thus, the policymaker adopts a more prudent, or precautionary, standpoint. ${ }^{14}$

Note also that with rising mitigation costs, optimal policies become more defensive. When a reduction in emissions is more expensive, the policymaker reacts with more patience and the optimal path to equilibrium is prolonged. Thus it is no surprise that losses also rise when mitigation costs increase. In contrast, a rise in the stabilization preference parameter leads to more aggressive policies in order to reduce the atmospheric carbon content. For higher mitigation costs the results appear to be very robust, since optimal policies and losses are nearly identical for all preference

\footnotetext{
${ }^{13}$ The only exception is the first row in Figure 2, where reaction parameters on $c a_{t}$ are positive, due to the negative preference parameter.

${ }^{14}$ This result is similar to the findings of Roughgarden and Schneider (1999) obtained in a different setting.
} 
parameters. Furthermore, optimal reaction functions for $\lambda=202600 \$ / \mathrm{Gt}^{2}$ and $\lambda=224000 \$ / \mathrm{Gt}^{2}$ do not differ substantially.

To illustrate the differences due to uncertainty, we simulate the paths for $c a_{t}$ and $c o_{t}$ for three different stabilisation scenarios: In the first scenario the policymaker tries to stabilize the carbon concentration on today's value, which is assumed to be $760 \mathrm{Gt}$ of carbon equivalent. ${ }^{15}$ Due to (5) the corresponding equilibrium amount of $\mathrm{CO}_{2}$ emissions is $7.68 \mathrm{Gt}$ carbon equivalent. For the second scenario we assume there exists a policymaker who wants to reduce the carbon concentration to 600 Gt, which implies equilibrium emissions of $6.06 \mathrm{Gt}$. Scenario 3 refers to stabilizing the atmospheric concentration at $500 \mathrm{Gt}$, which leads to $5.05 \mathrm{Gt}$ equilibrium emissions. As optimal policies do not differ much for high values of $\lambda$, and medium values for $\gamma$, simulations are done for $\lambda=\{0.14,2.45\}$ and $\gamma=\{5600,202600\}$. For all simulations we use starting values for $C A$ of $760 \mathrm{Gt}$ and for $C O$ of 8 Gt. The resulting graphs are shown in Figure 2 and confirm the indications of Table 1. We run simulations for the standard optimal policy without a concern for robustness (-), for the robust solution under uncertainty $(\mathrm{x})$, and for the robust rule in the approximating model without evil agent (o).

Several insights emerge from this exercise. The impulse response functions suggest that emissions should be stabilized within the next 5-7 years. However, the stabilization of atmospheric carbon content would nevertheless need approximately 400 years. With regard to the results under uncertainty, the Figures show, that emissions reductions are prolonged by 2-3 years when we introduce the evil agent, although the policy is more aggressive.

Whereas the robust emission reductions differ substantially from both the non-robust results and the robust policy in the approximating model, the evolution of the atmospheric carbon content seems to be very similar for all simulations and scenarios, except for scenario I. When the aim of the policymaker is to stabilise the atmospheric carbon content on today's level, the concentration rises first by a small amount, before it returns slowly to its equilibrium value. The robust and non-robust dynamics look very similar, but using the robust rule in the approximating environment - the case of unfounded fear of model misspecification - reduces the carbon content much faster than in either of the other cases. Comparing the two corresponding columns of Table 1 suggests that the policymaker allows the atmospheric content of carbon to stay above equilibrium for a longer time horizon when the mitigation costs rise. This can be seen best for a high stabilisation preference. Figure 2 shows the plausible result that, for a higher preference of stabilisation, emissions should be reduced by a greater amount, as this brings about a faster decrease in the atmospheric carbon content. In addition, the Figure 2 illustrates that for a policymaker with a high stabilization preference, whose aim is to stabilize the atmospheric carbon content at a lower level than that of today, and for low mitigation

\footnotetext{
${ }^{15}$ This is in line with the latest estimation of the IPCC of 370 ppmv, see Metz (2005).
} 
costs, it can be optimal to reduce emissions very sharply and keep them below their equilibrium value for a long time, in order to enforce the reduction of the atmospheric content of carbon.

Figure 2: Model Simulations

Scenario I: CA $=760 \mathrm{Gt}, \mathrm{CO}=7.68 \mathrm{Gt}$

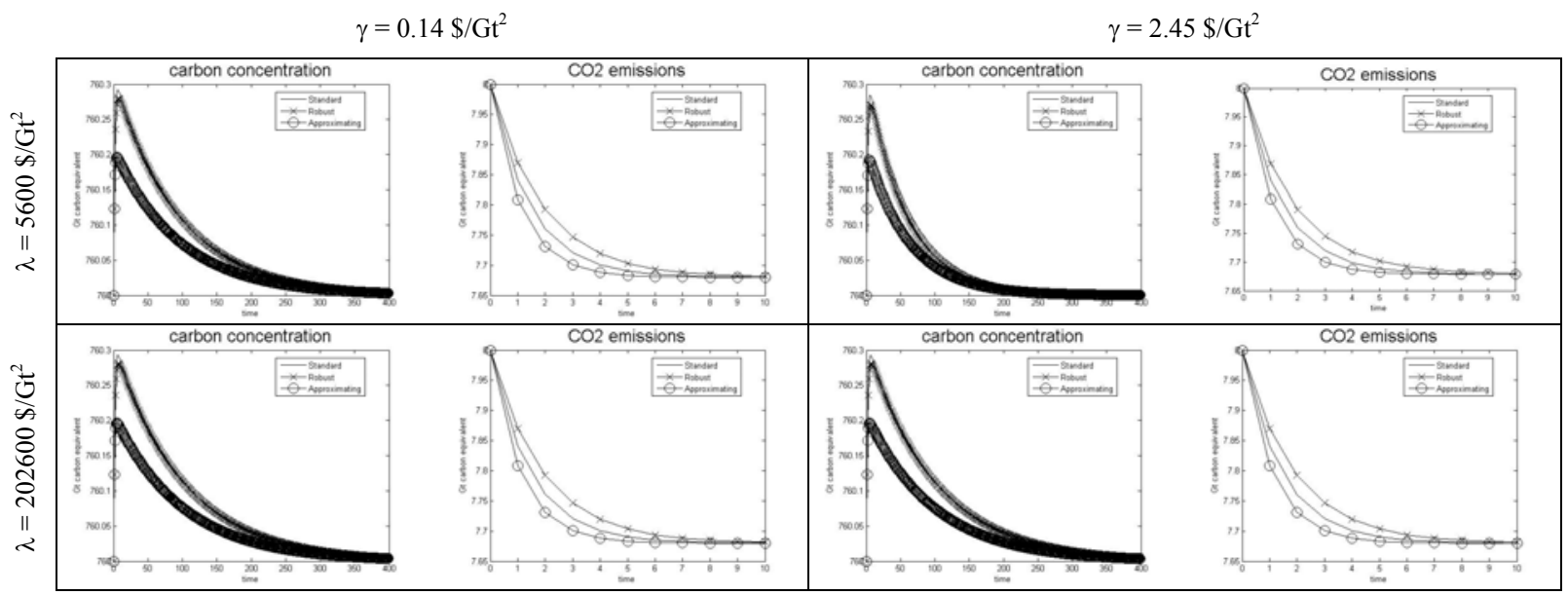

Scenario II: CA $=600 \mathrm{Gt}, \mathrm{CO}=6.06 \mathrm{Gt}$

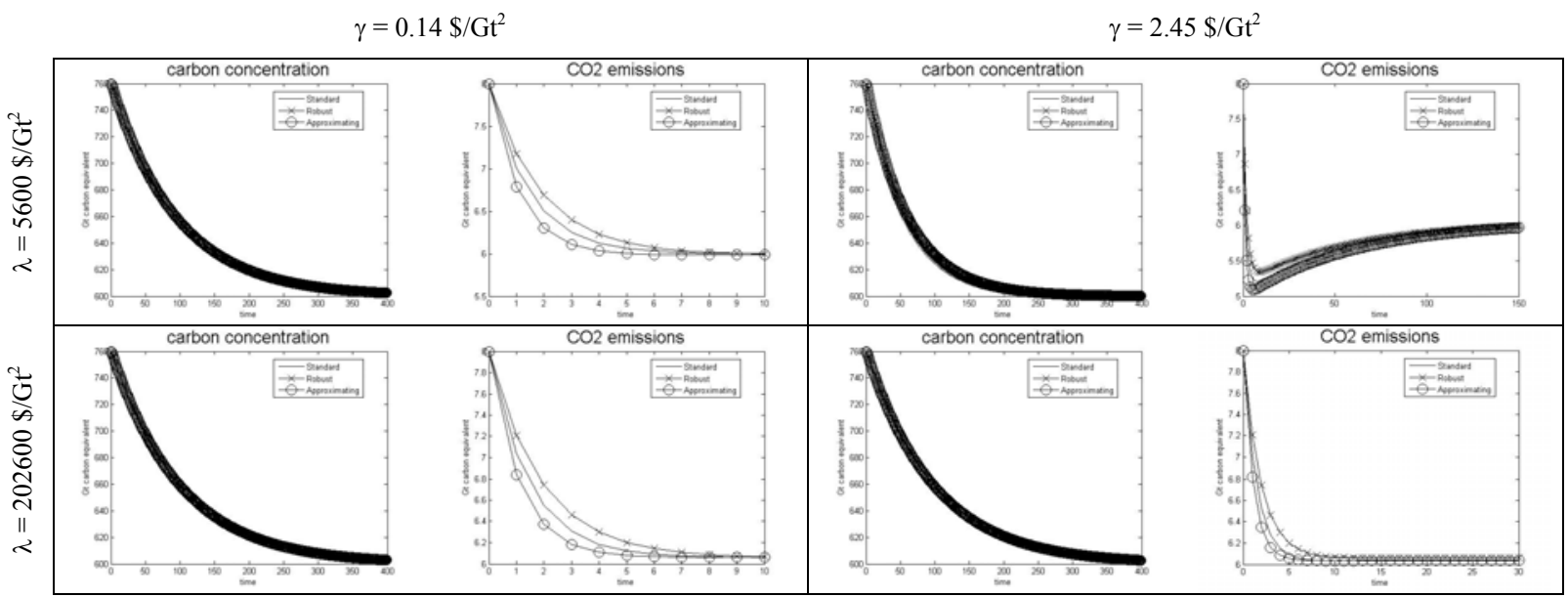

Scenario III: CA $=500$ Gt, $\mathrm{CO}=5.05 \mathrm{Gt}$

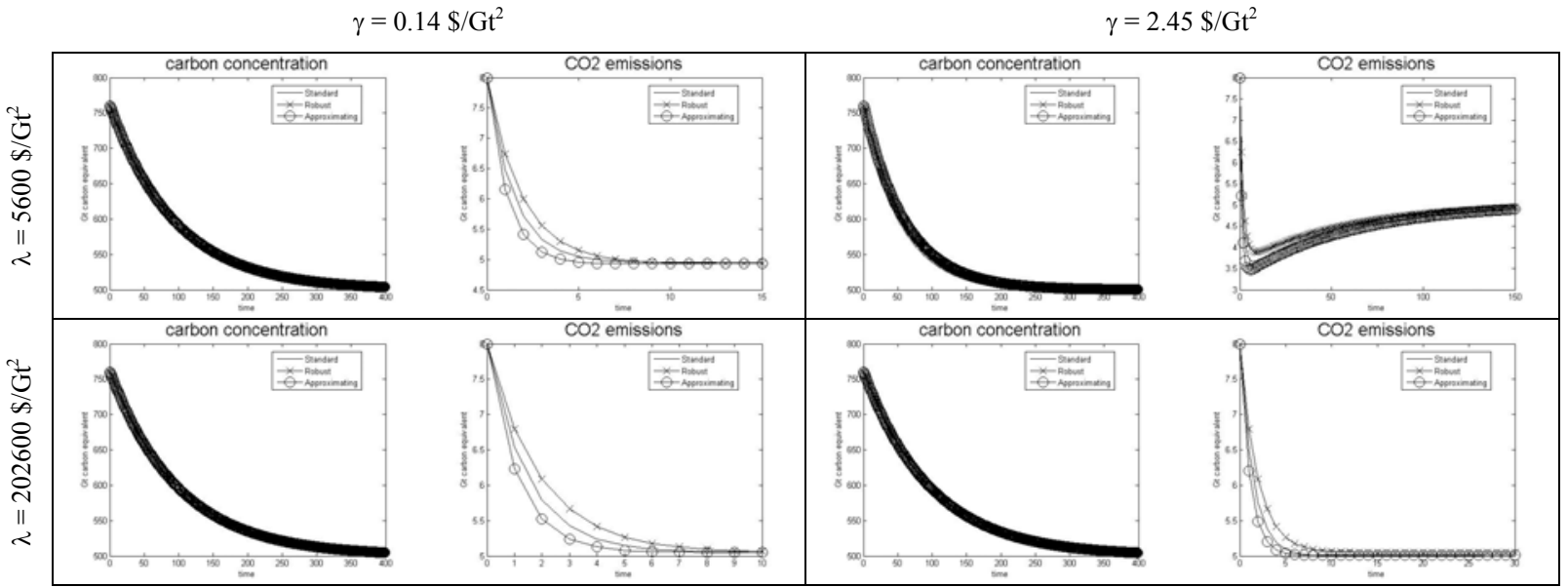


All simulations illustrate that the introduction of a second malevolent player implies a higher emissions trajectory, although the reduction policy is more aggressive. This is compatible with the increase in losses due to uncertainty, shown in Table 1. Using the robust solution in the approximating model illustrates the increased aggressiveness in stabilisation policies, since $c a_{t}$ as well as $\mathrm{CO}_{t}$ reach their equilibrium faster. A robust environmental policymaker fears stronger damages from not reducing emissions, and thus chooses a more aggressive reduction policy. Viewed from the opposite perspective, model uncertainty does not justify conservatism.

\section{Conclusions}

This paper develops a linear quadratic approach to study optimal emissions paths subject to stabilisation preferences and mitigation costs for three different scenarios: (i) a stabilisation on today's atmospheric carbon content (760 Gt carbon equivalent), (ii) a reduction to $600 \mathrm{Gt}$ carbon equivalent, (ii) and a reduction to $500 \mathrm{Gt}$ carbon equivalent. For a plausible model specification the results suggest that emissions should be stabilized within the next 5-7 years, independent of the underlying stabilisation scenario. However, even for a stabilisation of emissions within the next 7 years, the atmospheric carbon content will need about 400 years to reach its steady state. Furthermore, we investigate optimal reduction policies under uncertainty, using the appealing HS robust control technique.

What can policymakers who have a preference for robustness of optimal policy with respect to misspecification of the underlying model learn from this research? What kind of response is appropriate to the climate threat? The optimal policy trajectories lead to the conclusion that a policymaker who fears model misspecification should react more aggressively. This qualitative result resembles those of monetary policy under model uncertainty. ${ }^{16}$

Although the example of $\mathrm{CO}_{2}$ emissions is used to demonstrate the robust modelling approach, the method is transferable to other environmental problems surrounded by model uncertainties. We hope that further applications of the robust modelling technique will soon follow, making use of increasing processor speeds which makes robustness analysis feasible for larger climate models requiring more computational time. By doing this, the gap between robust control theory and its application may close.

16 Giannoni (2002), Kilponen (2004), Leitemo and Söderström (2004), Onatski and Stock (2002) and Söderström (2002) have examined whether model uncertainty justifies cautious central bankers. The overall conclusion is that robustness against model misspecification makes monetary policy respond more aggressively to shocks. 


\section{References:}

Baker, E. (2005) "Uncertainty and Learning in a Strategic Environment: Global Climate Change", Resource and Energy Economics 27, 19-40.

Baker, E., Clarke, L. and Weyant, J.P. (2006) "Optimal Technology R\&D in the Face of Climate Uncertainty", Climatic Change 78, 157-179.

Brainard, W. (1967) "Uncertainty and the Effectiveness of Policy”, American Economic Review 57, 411-425.

Giannoni, M.P. (2002) "Does Model Uncertainty Justify Caution? Robust Optimal Monetary Policy in a Forward-Looking Model", Macroeconomic Dynamics 6, 111-144.

Hansen, L.P. and Sargent, T.J. (2000) "Wanting Robustness in Macroeconomics", University of Chigaco, Stanford University and Hoover Institution, unpublished paper.

Hansen, L.P. and Sargent, T.J. (2003) "Robust Control of Forward Looking Models", Journal of Monetary Economics 50, 581-604.

Hansen, L.P. and Sargent, T.J. (2007) Robustness, Princeton University Press (forthcoming).

Ingham, A. and Ulph, A. (2003) "Uncertainty, Irreversibility, Precaution and the Social Cost of Carbon”, Tyndall Centre Working Paper 37.

IPCC, Intergovernmental Panel on Climate Change (2000) Special Report on Emissions Scenarios (SRES), Cambridge University Press, Cambridge UK.

IPCC, Intergovernmental Panel on Climate Change (2001) Climate Change 2001 - Third Assessment Report (TAR), Cambridge University Press, Cambridge UK.

Keller, K., Bolker, B.M. and Bradford, D.F. (2004) "Uncertain Climate Thresholds and Optimal Economic Growth", Journal of Environmental Economics and Management 48, 723-741.

Kilponen, J. (2004) "Robust Expectations and Uncertain Models - A Robust Control Application to the New Keynesian Economy", Bank of Finland Discussion Papers 5/2004, Helsinki.

Leitemo, K. and Söderström, U. (2004) "Robust Monetary Policy in the New-Keynesian Framework", CEPR Discussion Paper No. 4805, London.

Metz, B., Davidson, O., de Coninck, H., Loos, M. and Meyer, L. (2005) Carbon Dioxide Capture and Storage, Intergovernemental Panel on Climate Change Special Report.

Onatski, A. and Stock, J.H. (2002) "Robust Monetary Policy under Model Uncertainty in a Small Model of the U.S. Economy", Macroeconomic Dynamics 6, 85-110.

Pindyck, R.S. (2000) "Irreversibilities and the Timing of Environmental Policy", Resource and Energy Economics 22, 233-259

Pindyck, R.S. (2001) "Optimal Timing Problems in Environmental Economics", Journal of Economic Dynamics and Control 26, 1677-1697.

Roseta-Palma, C. and Xepapadeas, A. (2004) "Robust Control in Water Management", Journal of Risk and Uncertainty 29, 21-34. 
Roughgarden, T. and Schneider, S.H. (1999) "Climate Change Policy: Quantifying Uncertainties for Damages and Optimal Carbon Taxes", Energy Policy 27, 415-429.

Söderström, U. (2002) "Monetary Policy with Uncertain Parameters", Scandinavian Journal of Economics 104, 125-145.

Svensson, L.E. O. (2002) "Robust Control Made Simple", Princeton University, unpublished paper.

Tol, R.S.J. (2005) "The Marginal Damage Costs of Carbon Dioxide Emissions: An Assessment of the Uncertainties", Energy Policy 33, 2064-2074.

Van Vuuren, D.P., Weyant, J., de la Chesnaye, F.C. (2006) "Multi-Gas Scenarios to Stabilize Radiative Forcing", Energy Economics 28, 102-130.

Webster, M. (2002) “The Curious Role of 'Learning' in Climate Policy: Should We Wait for More Data?”, Energy Journal 23, 97-119.

Webster, M., Forest, C., Reilly, J.M., Babiker, M., Kicklighter, D.W., Mayer, M., Prinn, R., Sarofim, M., Sokolov, A., Stone, P. and Wang, C. (2003) "Uncertainty Analysis of Climate Change and Policy Response", Climatic Change 61, 295-320. 


\section{CESifo Working Paper Series}

(for full list see www.cesifo-group.de)

1876 Agnieszka Stążka, Sources of Real Exchange Rate Fluctuations in Central and Eastern Europe - Temporary or Permanent?, December 2006

1877 Xavier Calsamiglia, Teresa Garcia-Milà and Therese J. McGuire, Why do Differences in the Degree of Fiscal Decentralization Endure?, December 2006

1878 Natacha Gilson, How to be Well Shod to Absorb Shocks? Shock Synchronization and Joining the Euro Zone, December 2006

1879 Scott Alan Carson, Modern Health Standards for Peoples of the Past: Biological Conditions by Race in the American South, 1873 - 1919, December 2006

1880 Peter Huber, Michael Pfaffermayr and Yvonne Wolfmayr, Are there Border Effects in the EU Wage Function?, December 2006

1881 Harry Flam and Håkan Nordström, Euro Effects on the Intensive and Extensive Margins of Trade, December 2006

1882 Panu Poutvaara and Mikael Priks, Hooliganism in the Shadow of the 9/11 Terrorist Attack and the Tsunami: Do Police Reduce Group Violence?, December 2006

1883 Ruud A. de Mooij and Gaëtan Nicodème, Corporate Tax Policy, Entrepreneurship and Incorporation in the EU, December 2006

1884 Johannes Becker and Clemens Fuest, Corporate Tax Policy and International Mergers and Acquisitions - Is the Tax Exemption System Superior?, January 2007

1885 Momi Dahan and Udi Nisan, The Effect of Benefits Level on Take-up Rates: Evidence from a Natural Experiment, January 2007

1886 José García-Solanes, Francisco I. Sancho-Portero and Fernando Torrejón-Flores, Beyond the Salassa-Samuelson Effect in some New Member States of the European Union, January 2007

1887 Peter Egger, Wolfgang Eggert and Hannes Winner, Saving Taxes Through Foreign Plant Ownership, January 2007

1888 Timothy J. Goodspeed and Andrew Haughwout, On the Optimal Design of Disaster Insurance in a Federation, January 2007

1889 Wim Groot, Henriëtte Maassen van den Brink and Bernard van Praag, The Compensating Income Variation of Social Capital, January 2007

1890 Bas Jacobs, Ruud A. de Mooij and Kees Folmer, Analyzing a Flat Income Tax in the Netherlands, January 2007 
1891 Hans Jarle Kind, Guttorm Schjelderup and Frank Stähler, Newspapers and Advertising: The Effects of Ad-Valorem Taxation under Duopoly, January 2007

1892 Erkki Koskela and Rune Stenbacka, Equilibrium Unemployment with Outsourcing under Labour Market Imperfections, January 2007

1893 Maarten Bosker, Steven Brakman, Harry Garretsen, Herman de Jong and Marc Schramm, The Development of Cities in Italy 1300 - 1861, January 2007

1894 Michel Beine, Oscar Bernal, Jean-Yves Gnabo and Christelle Lecourt, Intervention Policy of the BoJ: A Unified Approach, January 2007

1895 Robert S. Chirinko and Daniel J. Wilson, State Investment Tax Incentives: A Zero-Sum Game?, January 2007

1896 Theo S. Eicher and Oliver Roehn, Sources of the German Productivity Demise Tracing the Effects of Industry-Level ICT Investment, January 2007

1897 Helge Berger, Volker Nitsch and Tonny Lybek, Central Bank Boards around the World: Why does Membership Size Differ?, January 2007

1898 Gabriel Felbermayr and Wilhelm Kohler, Does WTO Membership Make a Difference at the Extensive Margin of World Trade?, January 2007

1899 Benno Torgler and Friedrich Schneider, The Impact of Tax Morale and Institutional Quality on the Shadow Economy, January 2007

1900 Tomer Blumkin and Efraim Sadka, On the Desirability of Taxing Charitable Contributions, January 2007

1901 Frederick van der Ploeg and Reinhilde Veugelers, Higher Education Reform and the Renewed Lisbon Strategy: Role of Member States and the European Commission, January 2007

1902 John Lewis, Hitting and Hoping? Meeting the Exchange Rate and Inflation Criteria during a Period of Nominal Convergence, January 2007

1903 Torben M. Andersen, The Scandinavian Model - Prospects and Challenges, January 2007

1904 Stephane Dees, Sean Holly, M. Hashem Pesaran and L. Vanessa Smith, Long Run Macroeconomic Relations in the Global Economy, January 2007

1905 Richard Jong-A-Pin and Jakob De Haan, Political Regime Change, Economic Reform and Growth Accelerations, January 2007

1906 Sascha O. Becker and Peter H. Egger, Endogenous Product versus Process Innovation and a Firm's Propensity to Export, February 2007 
1907 Theo S. Eicher, Chris Papageorgiou and Oliver Roehn, Unraveling the Fortunates of the Fortunate: An Iterative Bayesian Model Averaging (IBMA) Approach, February 2007

1908 Liliana E. Pezzin, Robert A. Pollak and Barbara S. Schone, Efficiency in Family Bargaining: Living Arrangements and Caregiving Decisions of Adult Children and Disabled Elderly Parents, February 2007

1909 Christian Keuschnigg and Soren Bo Nielsen, Self-Selection and Advice in Venture Capital Finance, February 2007

1910 Rune Jansen Hagen and Gaute Torsvik, Irreversible Investments, Dynamic Inconsistency and Policy Convergence, February 2007

1911 Eric A. Hanushek and Ludger Woessmann, The Role of School Improvement in Economic Development, February 2007

1912 Bernard M. S. van Praag, Perspectives from the Happiness Literature and the Role of New Instruments for Policy Analysis, February 2007

1913 Volker Grossmann and Thomas M. Steger, Growth, Development, and Technological Change, February 2007

1914 Margarita Katsimi and Thomas Moutos, Human Capital and the Feldstein-Horioka Puzzle, February 2007

1915 Oliver Roehn, Theo S. Eicher and Thomas Strobel, The Ifo Industry Growth Accounting Database, February 2007

1916 Ian Babetskii, Aggregate Wage Flexibility in Selected New EU Member States, February 2007

1917 Burkhard Heer, Alfred Maussner and Paul D. McNelis, The Money-Age Distribution: Empirical Facts and Limited Monetary Models, February 2007

1918 Yin-Wong Cheung, Menzie D. Chinn and Eijii Fujii, The Overvaluation of Renminbi Undervaluation, February 2007

1919 Jim Malley, Apostolis Philippopoulos and Ulrich Woitek, To React or Not? Fiscal Policy, Volatility and Welfare in the EU-3, February 2007

1920 Mattias Polborn, Competing for Recognition through Public Good Provision, February 2007

1921 Lars P. Feld and Benno Torgler, Tax Morale after the Reunification of Germany: Results from a Quasi-Natural Experiment, February 2007

1922 Robert S. Chirinko and Huntley Schaller, Fundamentals, Misvaluation, and Investment: The Real Story, February 2007 
1923 Benno Torgler and Friedrich Schneider, Shadow Economy, Tax Morale, Governance and Institutional Quality: A Panel Analysis, February 2007

1924 Adrian Pagan and M. Hashem Pesaran, On Econometric Analysis of Structural Systems with Permanent and Transitory Shocks and Exogenous Variables, February 2007

1925 Hans-Werner Sinn, The Welfare State and the Forces of Globalization, February 2007

1926 Michael Smart, Raising Taxes through Equalization, February 2007

1927 Øystein Foros, Kåre P. Hagen and Hans Jarle Kind, Price-Dependent Profit Sharing as an Escape from the Bertrand Paradox, February 2007

1928 Balázs Égert, Kirsten Lommatzsch and Amina Lahrèche-Révil, Real Exchange Rates in Small Open OECD and Transition Economies: Comparing Apples with Oranges?, February 2007

1929 Aleksander Berentsen and Cyril Monnet, Monetary Policy in a Channel System, February 2007

1930 Wolfgang Ochel, The Free Movement of Inactive Citizens in the EU - A Challenge for the European Welfare State?, February 2007

1931 James K. Hammitt and Nicolas Treich, Statistical vs. Identified Lives in Benefit-Cost Analysis, February 2007

1932 Wilhelm Kohler, The Bazaar Effect, Unbundling of Comparative Advantage, and Migration, February 2007

1933 Karsten Staehr, Fiscal Policies and Business Cycles in an Enlarged Euro Area, February 2007

1934 Michele Bernasconi and Paola Profeta, Redistribution or Education? The Political Economy of the Social Race, March 2007

1935 Axel Dreher, Martin Gassebner and Lars-H. R. Siemers, Does Terror Threaten Human Rights? Evidence from Panel Data, March 2007

1936 Naércio Aquino Menezes Filho and Marc-Andreas Muendler, Labor Reallocation in Response to Trade Reform, March 2007

1937 Gebhard Flaig and Timo Wollmershaeuser, Does the Euro-zone Diverge? A Stress Indicator for Analyzing Trends and Cycles in Real GDP and Inflation, March 2007

1938 Michael Funke and Michael Paetz, Environmental Policy Under Model Uncertainty: A Robust Optimal Control Approach, March 2007 